\title{
Analysis of Prestressed Concrete Multi-cell Box Girder Curved Bridge
}

\author{
Khairmode A. S. ${ }^{1}$, Kulkarni D. B. ${ }^{2}$ \\ ${ }^{1}$ PG Scholar, Department of Civil Engineering, RIT, Rajaramnagar, Maharashtra, India. \\ ${ }^{2}$ Professor, Department of Civil Engineering, RIT, Rajaramnagar, Maharashtra, India
}

\begin{abstract}
Prestressed concrete structures are widely used in all over the world. They give better performance with smaller cross sections. The prestressed concrete construction is more suitable for medium and long span bridges with heavy loads. Now the prestressed concrete system is also used in curved bridge with long span. It has become challenge to analyze this bridge deck due to geometric complexities and interaction between bending and torsion. In this paper, the analysis of horizontally curved prestressed concrete box girder bridge deck is studied by using three dimensional modeling and analysis. Section geometry, material properties and radius of curvature are same in all the models while angle of curvature is varying from $0^{\circ}$ to $90^{\circ}$ and angle of curvature are kept constant as $30^{\circ}, 60^{\circ}$ and $90^{\circ}$ and its radius of curvature varying from $25 \mathrm{~m}$ to 50 m.Analysis is carried out using the IRC Class $A A$ loading. The 3D Finite Element Models are prepared using SAP software. The results for stresses are observed by keeping the same material properties.
\end{abstract}

Keywords: Prestressed concrete, curved bridge, Finite element analysis, Indian Road Congress, Class AA load

\section{Introduction}

Horizontally curved bridges are the most reasonable options at complicated conditions where geometric restrictions and constraint of limited site space make difficult the adoption of standard straight superstructure. Usually these bridges has cellular cross section so that it can resists the high torsional moment economically. As compared to straight bridges a rare documentation on study of horizontally curved bridges has been available. There is no separate guideline available for the curved bridge in the current specification of IRC.

Ali R. Khaloo and M. Kafimosavi has studied about the enhancement of flexural design of horizontally curved prestressed bridges $^{(1)}$. The flexural behavior of horizontally curved prestressed(post tensioned) box bridges is studied with the help of three dimensional finite element modeling and analysis. The result of this study shows that the stress distribution in curved bridge is different in comparison to straight bridges.

AASHTO has given strict restrictions on the use of stress distribution formulas for horizontally curved bridges. But there is no special considerations has been made on the use of stress distribution formulas for prestressed bridge. There is very limited knowledge about behavior of prestressed curved bridges is available, both in AASHTO specifications and the literature.

In this paper, stresses at mid-span of the bridge were investigated due to prestressing using different angles of curvature. The main objectives of this research are to study the behavior of prestressed curved box bridges.

\section{Literature Survey}

- Ali R. Khaloo and M. Kafimosavi (Sept.2007): has studied the flexure behavior of curved prestressed box bridge by using finite modeling models and analysis. Bridge span, geometry of section and material properties are kept same, only the angle of curvature is varying from 0 to $90^{\circ}$.From result it is proposed that the distribution of tendons across the width should be varying for optimizing the bridge capacity. Also it is concluded that the reduction in resultant stress is possible because of prestressing.

- Vikash Khatri et al (Sept. 2012): has done the prestressing of steel concrete composite bridge. In their paper they studied the effect of the total area of steel girder, prestressing force required in the cable and stresses in the deck slab using span length from $20 \mathrm{~m}$ to $100 \mathrm{~m}$ and 4 girders and 5 girder systems. They concluded that prestressing force at zero deflection under dead and imposed load helps to eliminate shrinkage cracks and increase the stress levels in the deck slab.

- Suren Chen et al (2014): has analyzed comprehensive performance on eight bridge configurations of various degrees of skew and curvature with low to moderate seismic excitations which are characteristics of mountain west region. The result of this paper gives the impact on seismic performance due to the effect of skew and curvature with combined geometries. They also made the complexities of curvature, skew, direction of loading and boundary conditions which leads to informed design decisions practicing engineers in the future.

- Thomas Wilson et al (June 2015):has studied the seismic performance of a reinforced concrete curved and skewed bridge under vertical ground motion. The effect of vertical ground motion on skewed and curved bridge is presented for moderate to high seismic region. The ground motions selected are composed of a range of near-fault earthquake records with varying component characteristics such as site condition, fault distance, and vertical-to-horizontal acceleration ratios. This study indicates that excluding the components of vertical ground motion from analysis imposes a larger risk margin than previous. 


\section{International Journal of Science and Research (IJSR) \\ ISSN (Online): 2319-7064}

Index Copernicus Value (2013): 6.14 | Impact Factor (2015): 6.391

- J. Senthilvasan et al (April 2002): has carried out an experimental investigation on a continuous curved concrete bridge which has the twin-cell box girder system. The bridge was tested for moving heavy vehicle at different speeds. The strains and deflections due to heavy vehicles are recorded. The experimental results were compared with the results which are obtained from analytical interaction of bridge-vehicle model and with the bridge design code. It is concluded that dynamic amplification depends on position on span and location on cross section. Results shows that there is larger dynamic amplification in strains as that of in deflections.

\section{Problem Statement}

In this paper, it is proposed to carry out the Seismic behavior of Prestressed Concrete curved bridge deck under moving load. The four cell box girder with $12 \mathrm{~m}$ carriage width and $2 \mathrm{~m}$ deep is taken for the study. The prestressing force of $5000 \mathrm{KN}$ is applied on the tendons. The bridges with curvature angle of $30^{\circ}, 60^{\circ}$ and $90^{\circ}$ and varying radius of curvature from $25 \mathrm{~m}$ to $50 \mathrm{~m}$ are considered. results obtained by software are validated by available research papers.

\section{Finite Element Method}

The main advantage of Finite Element Method is that its universal acceptance for variety of problems. The finite element method is one of the method which handle all types of structure. The application of FEM to bridge problems will need a detailed understanding and knowledge of almost all the facets of advanced structural mechanics and numerical techniques which many times a design engineer may not have.

During the past two decades, the Finite Element Method (FEM) has become a popular technique in engineering for computerized complex solutions. The FEM solves the problem by using mathematical modeling in which the structure should be considered as assembly of two or three dimensional elements connected to each other at their nodal points, possessing an appropriate number of degrees of freedom.

The entire structure (Box Girder) is divided into small elements and the stiffness of that structure is assembled from the membrane and the plate bending stiffness of each element.

\section{Analysis}

The study of stresses of horizontally curved prestressed concrete box bridges is presented by using three dimensional finite element analysis software SAP 2000.The multi-cell box girder bridge with different angles of curvatures were selected for the study of stress distribution. All the bridges has radius of $40 \mathrm{~m}$ and the Curvature angles varying from $0^{0}$ to $90^{\circ}$. The corresponding spans are from $13.96 \mathrm{~m}$ to $62.83 \mathrm{~m}$ in length. The geometry of bridge is as shown in the Fig.1

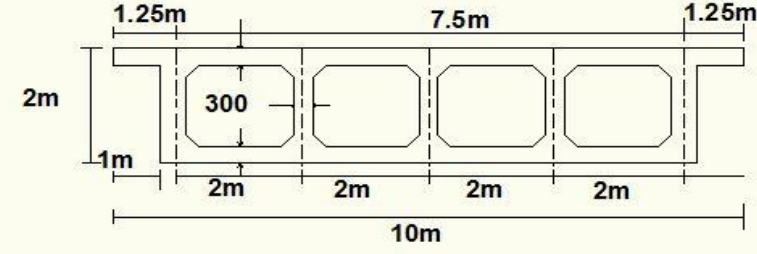

Figure 1: Cross section adopted

At both the ends of the bridge $30 \mathrm{~cm}(1 \mathrm{ft})$ diaphragm are provided which reduce local effects and provide uniform distribution of the large support reactions. All these bridges contain two traffic lanes. Profile adopted for prestressing tendon is as shown in the figure 2. These prestressing tendons are distributed in the 5 web girders with the tensile force of $5000 \mathrm{KN}$ per tendon.

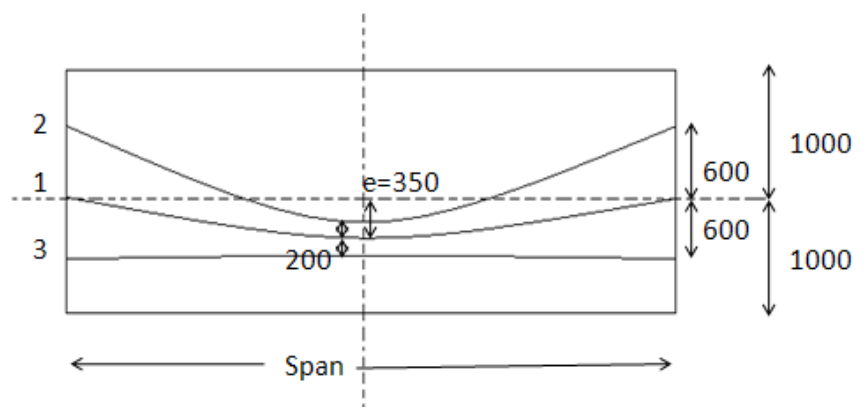

Figure 2: Profile of tendon in curved bridge.

\subsection{Live load consideration}

All the models are designed for class AA loading. According to IRC specification the bridge designed for class AA loading should be checked for class A loading also, because the maximum bending moments are occurred due to class A loading.

The carriage width of bridge is $8.4 \mathrm{~m}$. Therefore according to IRC number of lanes should be 2 and live load combinations are 1 lane of $70 \mathrm{R}$ vehicle or 2 lanes of class A vehicle.



Figure 3: FEM Bridge model for curved bridge. 


\section{International Journal of Science and Research (IJSR) \\ ISSN (Online): 2319-7064}

Index Copernicus Value (2013): 6.14 | Impact Factor (2015): 6.391

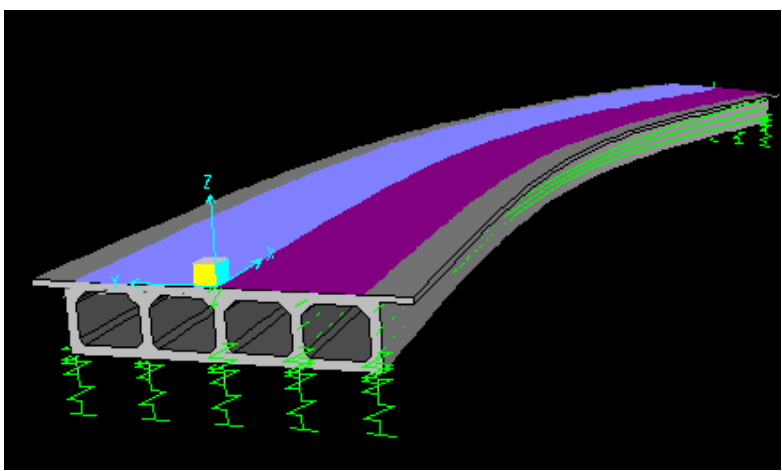

Figure 4: Extruded curved bridge model

\section{Result and Discussion}

The stress distribution in the bridges due to prestressing is listed in the Table 1 and 2.The distribution of stress is not symmetrical in prestressed curved box girder bridges. For prestressing load case, the longitudinal stresses increases at the internal part of the section and goes on decreasing towards the external edge. All the section area is still in compression and within AASHTO limits.

\subsection{Midspan Longitudinal Stresses}

The longitudinal stresses at top and bottom level of the bridge deck are obtained. These longitudinal stresses are obtained for prestress loading case. The values of stresses are negative which means that stresses are in compression.

Table 1: Mid span Stress Distribution for curvature angle $30^{0}$

\begin{tabular}{|c|c|c|c|}
\hline Radius(m) & Span(m) & \multicolumn{2}{|c|}{ Longitudinal Stress(MPa) } \\
\cline { 3 - 4 } & & Top & Bottom \\
\hline 25 & 13.09 & -4.66 & -1.22 \\
\hline 30 & 15.708 & -4.38 & -1.67 \\
\hline 35 & 18.326 & -4.53 & -1.75 \\
\hline 40 & 20.94 & -4.67 & -0.96 \\
\hline 45 & 23.56 & -4.82 & -0.83 \\
\hline 50 & 26.18 & -2.22 & -1.33 \\
\hline
\end{tabular}

Table 2: Mid span Stress Distribution for curvature angle $60^{\circ}$

\begin{tabular}{|c|c|c|c|}
\hline \multirow{2}{*}{ Radius(m) } & \multirow{2}{*}{ Span(m) } & \multicolumn{3}{|c|}{ Longitudinal Stress(MPa) } \\
\cline { 3 - 4 } & & Top & Bottom \\
\hline 25 & 26.18 & -2.17 & -13.30 \\
\hline 30 & 31.42 & -2.12 & -12.96 \\
\hline 35 & 36.65 & -4.56 & -2.85 \\
\hline 40 & 41.89 & -2.03 & -3.07 \\
\hline 45 & 47.12 & -2.19 & -4.51 \\
\hline 50 & 52.36 & -3.946 & -1.787 \\
\hline
\end{tabular}

Table 3: Mid span Stress Distribution for curvature angle $90^{\circ}$

\begin{tabular}{|c|c|c|c|}
\hline Radius(m & \multirow{2}{*}{ Span(m) } & \multicolumn{2}{|c|}{ Longitudinal Stress(MPa) } \\
\cline { 3 - 4 } & & Top & Bottom \\
\hline 25 & 39.27 & -3.76 & -2.79 \\
\hline 30 & 47.12 & -3.71 & -2.69 \\
\hline 35 & 54.98 & -3.43 & -3.37 \\
\hline 40 & 62.83 & -3.39 & -3.24 \\
\hline 45 & 70.69 & -3.21 & -4.21 \\
\hline 50 & 78.54 & -2.95 & -4.37 \\
\hline
\end{tabular}

\section{Top Stress Distribution}

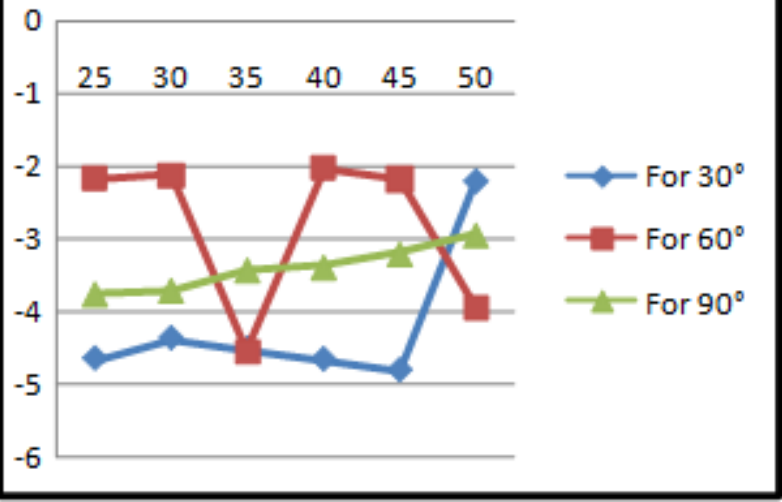

Figure 4: Top stress distribution

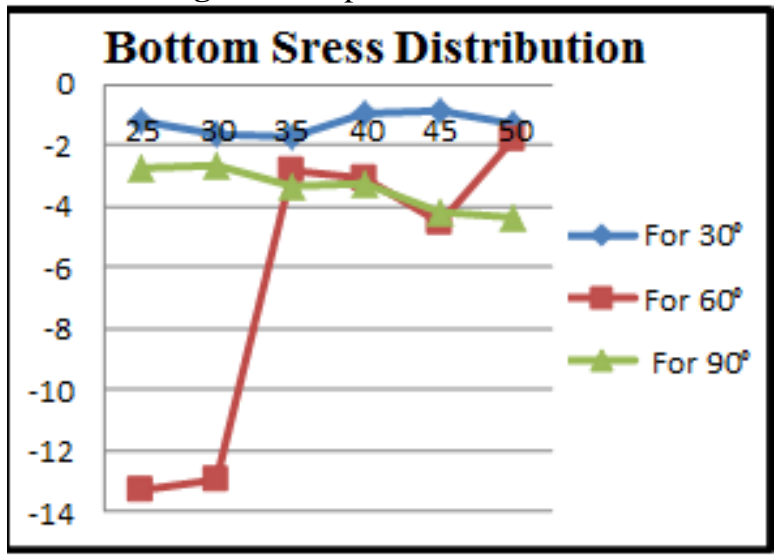

Figure 5: Bottom stress distribution

Table 4: Mid span Stress Distribution for radius of curvature $40 \mathrm{~m}$

\begin{tabular}{|c|c|c|c|}
\hline \multirow{2}{*}{$\begin{array}{c}\text { Curvature } \\
\text { angle }\end{array}$} & Span(m) & \multicolumn{2}{|c|}{ Longitudinal Stress(MPa) } \\
\cline { 3 - 4 } & & Top & Bottom \\
\hline $20^{0}$ & 13.96 & -4.67 & -1.57 \\
\hline $30^{0}$ & 20.94 & -4.66 & -0.959 \\
\hline $40^{0}$ & 27.92 & -4.39 & -1.509 \\
\hline $50^{0}$ & 34.91 & -4.65 & -1.677 \\
\hline $60^{0}$ & 41.89 & -4.015 & -1.955 \\
\hline $70^{0}$ & 48.87 & -3.887 & -2.109 \\
\hline $80^{0}$ & 55.85 & -3.64 & -2.72 \\
\hline $90^{0}$ & 62.83 & -3.54 & -2.67 \\
\hline
\end{tabular}

Table 5: Mid span Stress Distribution for radius of curvature $50 \mathrm{~m}$

\begin{tabular}{|c|c|c|c|}
\hline \multirow{2}{*}{$\begin{array}{c}\text { Curvature } \\
\text { angle }\end{array}$} & \multirow{2}{*}{$\begin{array}{c}\text { Span } \\
(\mathrm{m})\end{array}$} & \multicolumn{2}{|c|}{ Longitudinal Stress(MPa) } \\
\hline 200 & 13.96 & -4.529 & Bottom \\
\hline 300 & 20.94 & -2.224 & -1.404 \\
\hline 400 & 27.92 & -4.383 & -1.329 \\
\hline 500 & 34.91 & -4.232 & -1.195 \\
\hline 600 & 41.89 & -3.946 & -1.032 \\
\hline 700 & 48.87 & -3.714 & -1.787 \\
\hline 800 & 55.85 & -3.407 & -2.097 \\
\hline 900 & 62.83 & -2.953 & -2.921 \\
\hline
\end{tabular}




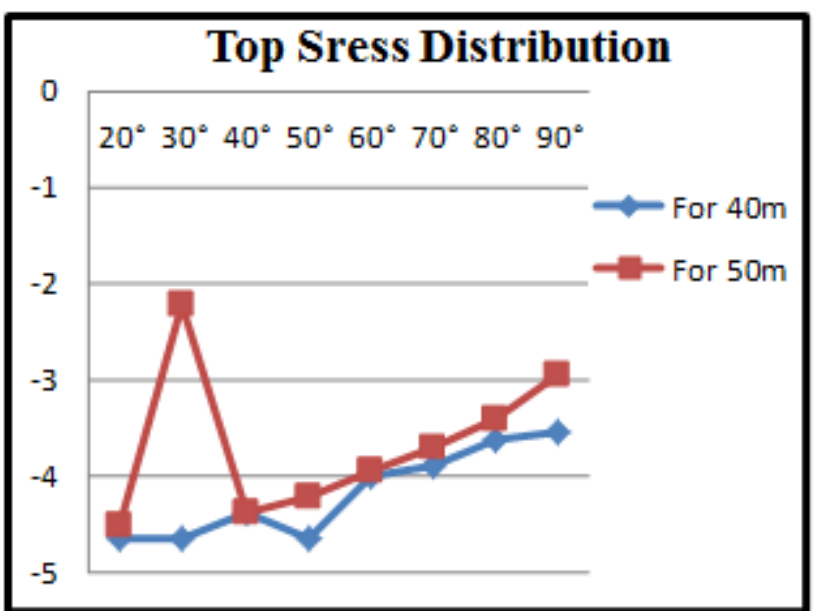

Figure 6: Top stress distribution

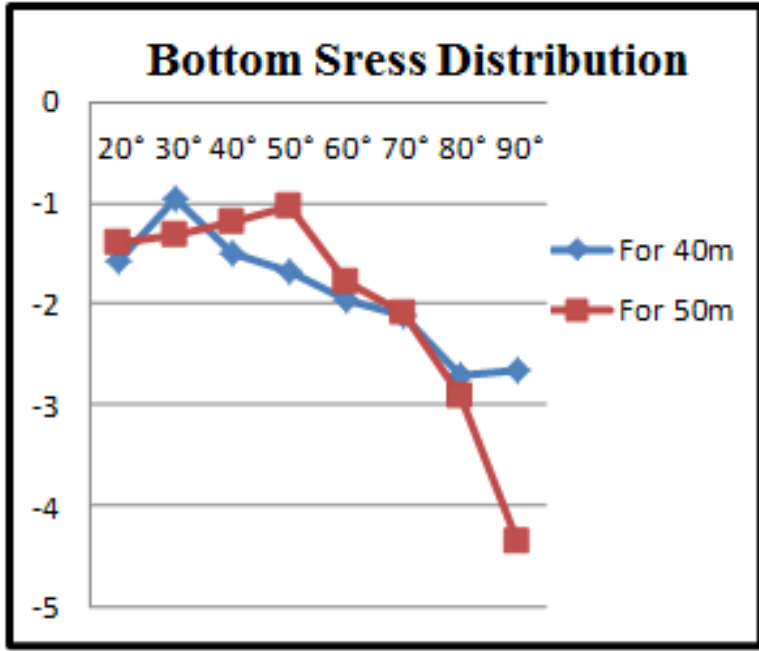

Figure 7: Bottom stress distribution

\subsection{Midspan Vertical Deflection}

The deflection is caused due to the different loadings to which the structure is subjected. The midspan deflection for all the models are computed.

Table 6: Midspan deflection for curvature angles

\begin{tabular}{|c|c|c|c|}
\hline $\begin{array}{c}\text { Radius of } \\
\text { Curvature }(\mathrm{m})\end{array}$ & $\begin{array}{c}\text { For } 30^{\circ} \text { in } \\
(\mathrm{m})\end{array}$ & $\begin{array}{c}\text { For } 60^{\circ} \text { in } \\
(\mathrm{m})\end{array}$ & For $90^{\circ}$ in $(\mathrm{m})$ \\
\hline 25 & 0.0841 & 0.0868 & 0.05027 \\
\hline 30 & 0.18 & 0.04 & 0.04735 \\
\hline 35 & 0.069 & 0.05 & 0.04265 \\
\hline 40 & 0.06508 & 0.048 & 0.03889 \\
\hline 45 & 0.0645 & 0.036 & 0.0376 \\
\hline 50 & 0.0615 & 0.0424 & 0.0349 \\
\hline
\end{tabular}

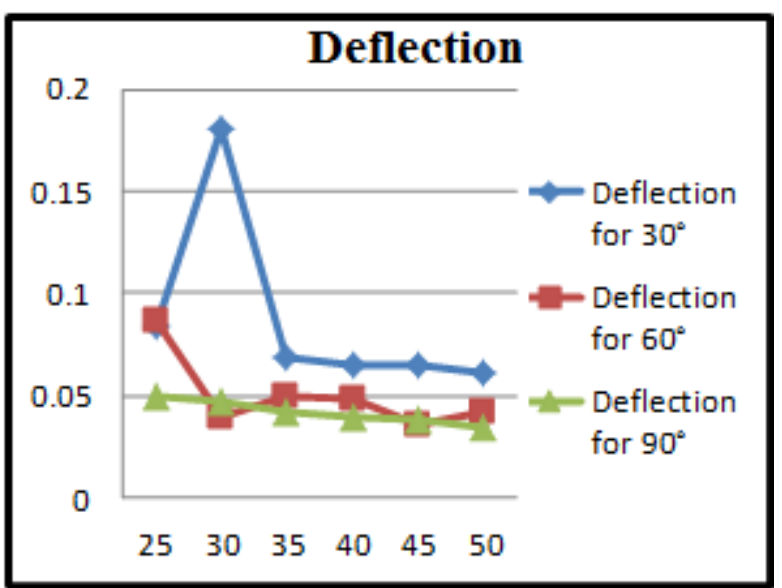

Figure 8: Midspan Vertical Deflection

Table 7: Midspan deflection for radius of curvature

\begin{tabular}{|c|c|c|}
\hline Angle of Curvature $(\mathrm{m})$ & For $40 \mathrm{~m}$ in $(\mathrm{m})$ & For 50 m in $(\mathrm{m})$ \\
\hline $20^{\circ}$ & 0.082326 & 0.07296 \\
\hline $30^{\circ}$ & 0.065082 & 0.0645 \\
\hline $40^{\circ}$ & 0.05837 & 0.051297 \\
\hline $50^{\circ}$ & 0.050788 & 0.046073 \\
\hline $60^{\circ}$ & 0.04887 & 0.0424 \\
\hline $70^{\circ}$ & 0.04373 & 0.039401 \\
\hline $80^{\circ}$ & 0.04238 & 0.037001 \\
\hline $90^{\circ}$ & 0.03994 & 0.0349 \\
\hline \multicolumn{2}{|c}{}
\end{tabular}

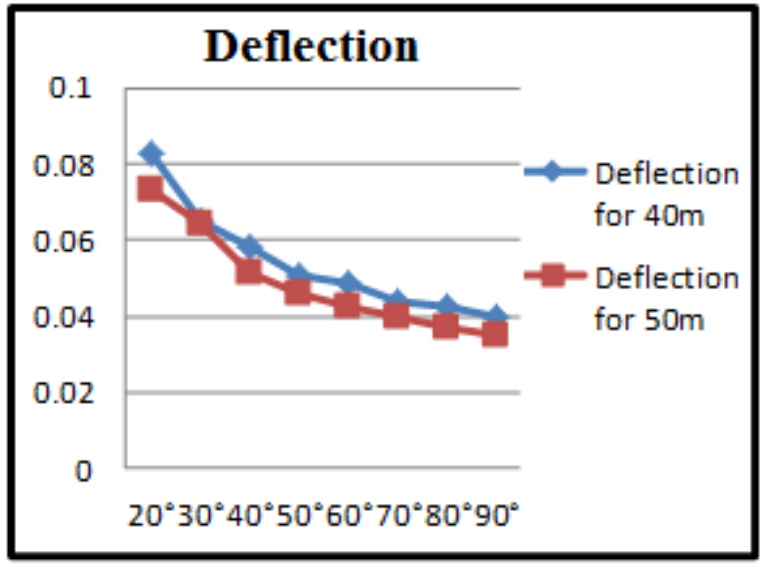

Figure 9: Midspan Vertical Deflection

\section{Conclusion}

With increase in the radius of curvature and angle of curvature, the stresses at the top of the prestressed curved bridges increases while stresses at the bottom of the bridges decreases. As the radius of curvature and angle of curvature of prestressed concrete curved bridge increases the midspan vertical deflection goes on decreasing.

\section{Future Scope}

- The performance of box girder by changing the profile and positions of the tendons.

- The performance of the deck can be investigated by changing the deck sections like trapezoidal or circuler shape.

- The effect due to change in boundry conditions and varying the loading conditions may be studied.

\section{Volume 5 Issue 6, June 2016} www.ijsr.net 
- The effect on continues span bridge can be computed in future study.

\section{References}

[1] Ali R. Khaloo and M. Kafimosavi(2007)“Enhancement of Flexural Design of Horizontally Curved Prestressed Bridges", Journal of bridge engineering, Vol.12, No.5,Septembar.

[2] Anagha S. Parkar,John B. Mander and Mery Beth (June2012) "Continuous Prestressed concrete girder bridge" Vol1,FHWA/TX-12/0-6651-1.

[3] Chirag Garg and M.V.N.Shivakumar (May2014) "Prestressed tendons system in box girder bridge" IJCE, 2278-9987, Vol 3,Isuue 3.

[4] IRC 6-2014 "Standard specifications and code of practice for road bridges",section-II loads and stresses,Indian Road Congress.New Delhi.

[5] IS1343-1980 Code of Practice for Prestressed Concrete.

[6] IS 1893-2002 Criteria for earthquake resistant design of structures.

[7] Mulesh K. Pathak (January 2014) "Performance of RCC Box type Superstructure in Curved bridges" International Journal of Scientific \& Engineering Research, Volume 5, Issue 1,ISSN 2229-5518.

[8] Nikhil Ingawale and D.B.Kulkarni (April2015) "Dynamic Analysis of reinforced concrete horizontally curved beam by software" IJERT,4(4).

[9] Nikhil Ingawale and D.B.Kulkarni (June2015) "Parametric study of horizontally curved bridge girder" IJOER,3(3).

\section{Author Profile}

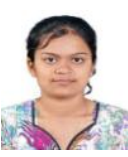

Khairmode A.S., student IV ${ }^{\text {th }}$ sem, M.tech structural engineering, Civil Engineering Department, Rajarambapu Institute of Technology, Rajaramnagar, Islampur, India.

Kulkarni D.B., Associate Professor, Civil Engineering Department, Rajarambapu Institute of Technology, Rajaramnagar, Islampur, India. 